\title{
Estudo da prevalência de anticorpos anti-Toxoplasma gondii em mulheres grávidas no Estado da Bahia
}

\section{Study of the prevalence of antibodies anti-Toxoplasma gondii in pregnant women in Bahia}

\author{
IVANA NASCIMENTOㄹ, SABRINA CARVALHO ${ }^{2}$, NIVALDO CARDOZO², SILVANA ASFORA², \\ ADRIANA CAMPOS ${ }^{2}$, SONGELI MENEZES ${ }^{4}$, JUÇARA SIMÕES ${ }^{3}$, ROBERT EDUARD SCHAER ${ }^{1}$, \\ ROBERTO MEYER
}

${ }^{1}$ Professor de Imunologia. Instituto de Ciências da Saúde. UFBA

${ }^{2}$ Bolsista de Iniciação Cientifica. Instituto de Ciências da Saúde. UFBA

${ }^{3}$ Farmacêutico Bioquimico. Instituto de Ciências da Saúde. UFBA

${ }^{4}$ Coordenadora do Programa de Pós-Graduação em Imunologia. Instituto de Ciências da Saúde. UFBA

\begin{abstract}
Resumo
A toxoplasmose é uma infecção causada pelo Toxoplasma gondii, que pode contaminar vários tipos celulares. A toxoplasmose congênita é considerada importante causa de mortalidade e morbidade infantis. No presente trabalho, foi avaliada a presença de anticorpos das classes IgM e IgG no soro de pacientes grávidas, correlacionando-se com o trimestre de gestação. Foram analisadas 5.946 amostras, sendo que 3.159 foram positivas para IgG, 42 para IgM e 2.745 foram soronegativas. A maioria das pacientes só foi encaminhada para a realização da sorologia a partir do segundo trimestre de gestação.
\end{abstract}

\section{Palavras-chave}

Toxoplasmose, Toxoplasma gondii, ELISA, infecções congênitas 


\section{Introdução}

A toxoplasmose é uma infecção causada por um parasita intracelular, o Toxoplasma gondii, que pode contaminar todos os tipos de células, porém tem uma maior afinidade pelo cérebro e músculo esquelético.

A incidência da infecção pelo Toxoplasma gondii é alta, apesar de a doença ter, freqüentemente, uma forma subclínica. $O$ risco de adquirir toxoplasmose durante a gestação correlaciona-se com a prevalência na comunidade, com o número de fontes de infecção e com o número de mulheres grávidas na comunidade com sorologia negativa para essa zoonose (FRENKEL, 1997).

A toxoplasmose congênita é considerada importante causa mundial de mortalidade e morbidade infantis. Estima-se que nasçam, anualmente no Brasil, cerca de sessenta mil crianças com a doença, sendo, portanto, de alta magnitude, podendo resultar em aborto, parto prematuro, natimorto e nascimento de malformado. A chance média de transmissão transplacentária é de $30 \%$. A gravidade é inversamente proporcional à idade gestacional e à facilidade de transmissão (MEIRELLES FILHO, 1985; NÓBREGA et al., 2002; STRAY-PEDERSEN, 1980).

O diagnóstico sorológico de infecção é feito através de pesquisa de anticorpos especificos detectados pelas reações de Sabin-Feldman, fixação de complemento, hemaglutinação passiva, imunofluorescência indireta e pelo método imunoenzimático (ELISA) com captura de anticorpos $\operatorname{IgM}$ e $\operatorname{IgG}$, que é o mais utilizado em nosso meio.

O presente trabalho teve como objetivo estudar a distribuição de amostras de soro de pacientes grávidas do Estado da Bahia, em diferentes estágios de gravidez, em relação ao resultado da análise ELISA para T. gondii.

\section{Materiais e métodos}

Foram analisadas 5.946 amostras para presença de anticorpos anti-T. gondii, sendo que 2.236 foram testadas para IgG especifico, 1.078 para IgM específico e 2.632 para ambas as classes.

\section{Amostras de soro}

As amostras de soro de pacientes grávidas, atendidas pelo Sistema Unificado de Saúde, provenientes de diversas regiões do Estado, foram analisadas no Laboratório de Imunologia do Instituto de Ciências da Saúde da UFBA, no periodo de janeiro de 1998 a julho de 2000 .

\section{ELISA}

A presença de anticorpos específicos antiT. gondii foi demonstrada através de ELISA indireta para IgG (Bioelisa, Bioktit S. A.) e ELISA captura para IgM (Bioelisa immunocapture, Biokit S. A.). Em ambos os casos, usou-se conjugados com peroxidase, o cromógeno foi o 3,3, 5,5 - Tetrametilbenzidina e a leitura da absorbância foi realizada a $450 \mathrm{~nm}$.

\section{Análise estatística}

Teste $t$ de Student.

\section{Resultados}

Das 5.946 amostras estudadas, 64,92\% (3.860) foram positivas para $\operatorname{IgG}, 1,19 \%$ (71) foram positivas para IgM e 33,89\% (2.015) foram soronegativas.

A FIG. 1 mostra a distribuição dos exames realizados para a detecção de anticorpos anti-T. gondii, em grávidas, nos anos de 1998, 1999 e 2000 (janeiro a julho), conforme o trimestre de gestação. Das pacientes avaliadas, 2.220 estavam no primeiro trimestre, 5.050 no segundo e 1.280 no terceiro trimestre de gestação.

No ano de 1998, 64,58\% das sorologias realizadas foram positivas para $\operatorname{IgG}$ e $1,42 \%$, para IgM; em 1999, 64,41\% foram positivas para IgG e 0,69\% para IgM; e em 2000, 65,77\% foram positivas para IgG e $1,46 \%$ para $\operatorname{IgM}$ (FIG. 2).

Na FIG. 3, pode-se observar a relação entre exames realizados e exames positivos conforme o trimestre de gestação. 


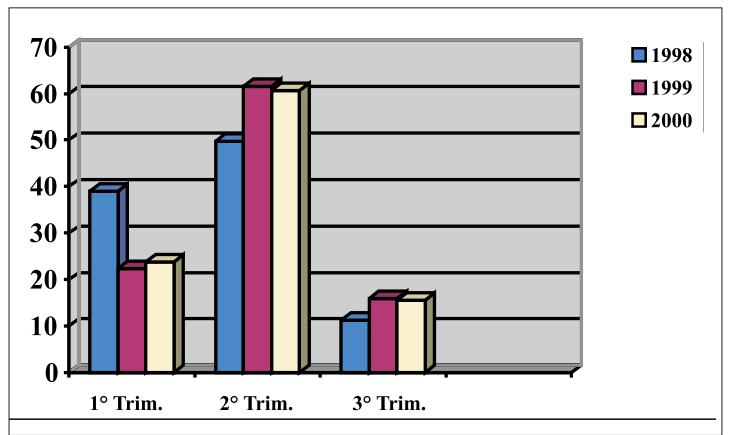

FIGURA 1

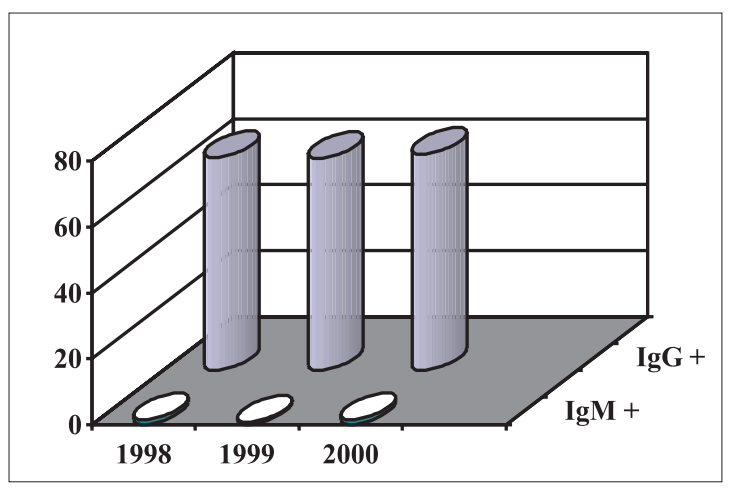

FIGURA 2

\section{Discussão e conclusões}

No Brasil, estudos sorológicos em grávidas mostraram taxas de positividade de $77,1 \%$ para IgG, no Rio de Janeiro, 1,4\% para IgM na cidade de São Paulo e 69,4\% e 2,4\% para IgG e IgM, respectivamente, em Pernambuco (MEIRELLES FILHO, 1985; NÓBREGA et al., 2002).

Os dados observados neste estudo permitem concluir que as taxas de positividade para IgG $(64,92 \%)$ e para IgM $(1,19 \%)$ em pacientes grávidas do Estado da Bahia não foram significativamente diferentes das observadas nos estudos acima mencionados. Um percentual significativo foi de pacientes soronegativas, que, em princípio, possuem risco de infecção durante a gestação.
PRIMEIROTRIMESTREDEGRAVIDEZ

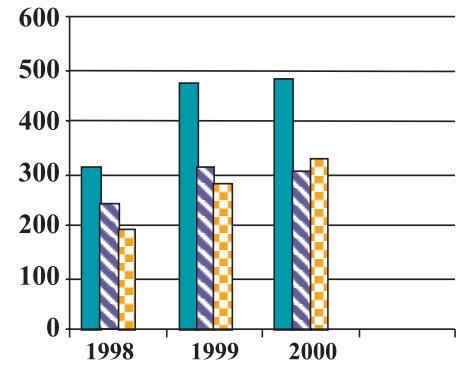

IgG Total

NIgM Total

EIgM +

$\square$ IgG +

\section{SEGUNDOTRIMESTREDEGRAVIDEZ}

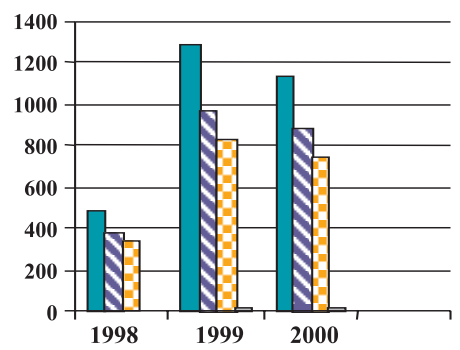

IgG Total

MIgM Total

밈 IgM +

$\square$ IgG +

\section{TERCEIROTRIMESTREDEGRAVIDEZ}

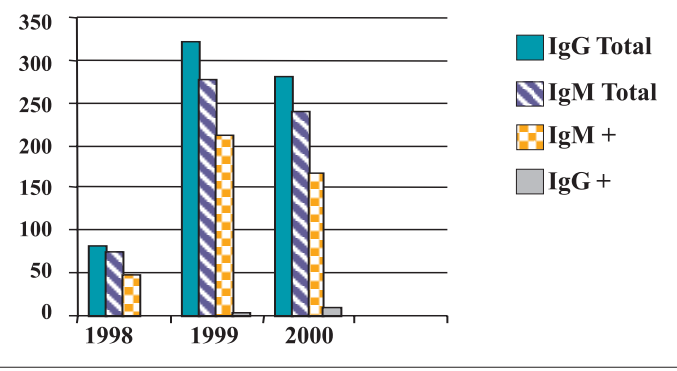

FIGURA 3

É importante observar que mais da metade das pacientes se submeteram aos exames a partir do segundo trimestre de gestação, apesar de estudos demonstrarem que o reconhecimento antecipado da infecção e o tratamento precoce reduzem a colonização do parasita na placenta e previnem a infecção do feto. Caso a infecção já tenha ocorrido, o tratamento modifica o curso da doença oferecendo um melhor prognóstico. (STRAYPEDERSEN, 1993; VAZ et al, 1990).

Este atraso em realizar os exames pré-natais pode ser resultado de uma maior dificuldade de acesso ao acompanhamento médico, desde quando as pacientes cujas amostras foram analisadas são atendidas pelo Sistema Único de Saúde. 


\begin{abstract}
Toxoplasmosis is an infection caused by Toxoplasma gondii, which may affect several kinds of cells. Congenital toxoplasmosis is considered an important cause of child mortality and morbility worldwide. In this paper we have evaluated the presence of $\operatorname{IgG}$ and $\operatorname{IgM}$ antibodies antiT. gondii during the pregnancy. From the 5.946 samples, 3.179 tested positive for $\operatorname{IgG}, 42$ positive for IgM and 2.745 were seranegative. Most patients were tested after the third month of pregnancy.
\end{abstract}

\title{
Key words
}

Toxoplasmosis, Toxoplama gondii, ELISA, congenital infections

\section{Referências}

FRENKEL, J. K. Toxoplasmose. In: VERONESI, R.; FOCCACIA, R. Tratado de infectologia. 2. ed. São Paulo: Ateneu, 1997. Cap. 99. p. 1290-1305.

MEIRELLES FILHO, J. Toxoplasmose e gravidez. Inquérito sorológico em gestantes e seus recém-nascidos na maternidade-escola da Universidade Federal do Rio de Janeiro. J. Bras. Ginec., v. 95, n. 9, p. 393-401, 1985.

NÓBREGA, M. C. et al. Toxoplasmose em gestantes e em seus recém-nascidos, atendidos no Hospital das Clínicas da

UFPE. Disponivel em: <http://www.aguia.redes.ufpe.br/ hcrm/prova1997.htm>. Acesso em: 17 mar. 2002.

STRAY-PEDERSEN, B. A prospective study of acquired toxoplasmosis among 8.043 pregnant women in the Oslo area. Am. J. Obstet. Gynecol., v. 136, n. 3, p. 339-406, 1980.

STRAY-PEDERSEN, B. Toxoplasmosis in pregnancy. Clin. Obstet. Gynecol., v. 7, 1. 1, p. 107-137, 1993.

VAZ, A. J. et al. Sorologia positiva para sifilis, toxoplasmose e doença de Chagas em gestantes de primeira consulta em centros de saúde da área metropolitana, Brasil. Saúde Pub., v. 24 , n. 5, p. 373-379, 1990. 